\title{
Modifying attitude and intention toward regular physical activity using protection motivation theory: a randomized controlled trial
}

Kamal Mirkarimi ${ }^{7}$, Maryam Eri ${ }^{1}$, Mohammad R. Ghanbari ${ }^{2}$, Mohammad J. Kabir ${ }^{7}$, Mojtaba Raeisi ${ }^{3}$, Rahman B. OzouniDavaji ${ }^{1}$, Mohammad Aryaie ${ }^{4}$ and Abdurrahman Charkazi ${ }^{5}$

$$
\begin{aligned}
& \text { تعديل الاتجاهات والنوايا نحو النشاط البدني المنتظم باستخدام نظرية التحفيز على الوقاية: تجربة معشاة ذات شواهد }
\end{aligned}
$$

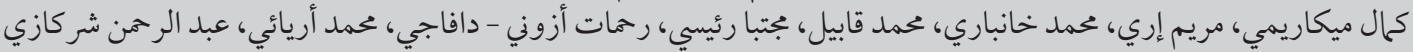

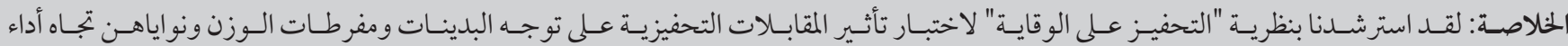

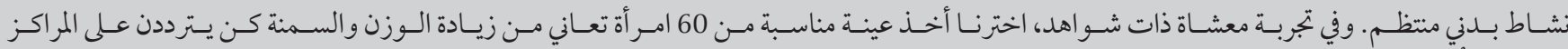

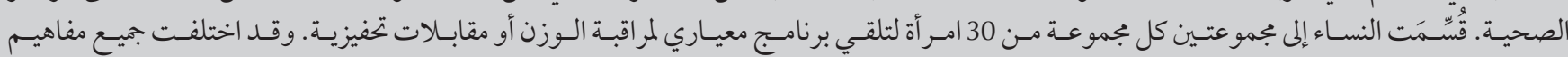

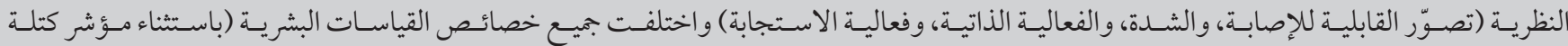

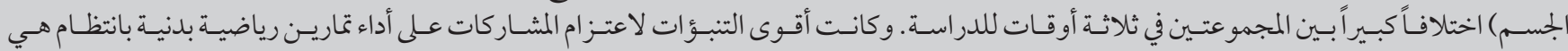

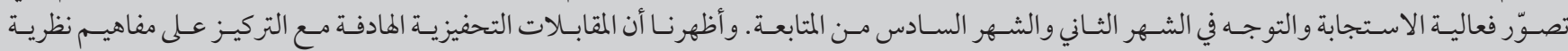

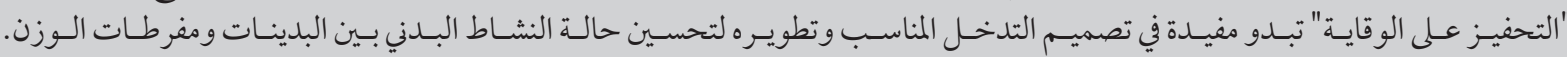

ABSTRACT We were guided by the Protection Motivation Theory to test the motivational interviewing effects on attitude and intention of obese and overweight women to do regular physical activity. In a randomized controlled trial, we selected using convenience sampling 60 overweight and obese women attending health centres. The women were allocated to 2 groups of 30 receiving a standard weight-control programme or motivational interviewing. All constructs of the theory (perceived susceptibility, severity, self-efficacy and response efficacy) and all anthropometric characteristics (except body mass index) were significantly different between the groups at 3 study times. The strongest predictors of intention to do regular physical exercise were perceived response efficacy and attitude at 2- and 6-months follow-up. We showed that targeting motivational interviewing with an emphasis on Protection Motivation Theory constructs appeared to be beneficial for designing and developing appropriate intervention to improve physical activity status among women with overweight and obesity.

Modification de l'attitude et de l'intention vis-à-vis d'une activité physique régulière à l'aide de la théorie de la motivation à la protection : essai contrôlé randomisé

RÉSUMÉ Nous nous sommes servis de la théorie à la motivation à la protection pour tester l'impact des entretiens motivationnels sur l'attitude et l'intention des femmes obèses et en surcharge pondérale vis-à-vis de la pratique d'une activité physique régulière. Lors d'un essai contrôlé randomisé, 60 femmes obèses et en surcharge pondérale se présentant dans des centres de santé ont été sélectionnées par échantillonnage de commodité. Les femmes ont été réparties en deux groupes, chaque groupe comprenant 30 femmes suivant un programme standard de gestion du poids ou assistant à des entretiens motivationnels. Les composantes de la théorie (vulnérabilité perçue, gravité, auto-efficacité et efficacité de la réponse) ainsi que les caractéristiques anthropométriques (sauf l'indice de masse corporelle) étaient toutes significativement différentes entre les groupes à trois moments de l'étude. Les indicateurs de l'intention les plus forts concernant la pratique régulière de l'exercice physique étaient l'efficacité de réponse perçue et l'attitude lors du suivi à deux et six mois. Nous avons prouvé que la réalisation des entretiens motivationnels en mettant l'accent sur la théorie de la motivation à la protection s'est avérée profitable pour la conception et l'élaboration des interventions appropriées afin d'améliorer le statut de l'activité physique chez les femmes obèses et en surcharge pondérale.

${ }^{1}$ Health Management and Social Development Research Center, Golestan University of Medical Sciences (Correspondence to: A. Charkazi: rcharkazi@yahoo. com). ${ }^{2}$ Department of Public Health, Golestan University of Medical Sciences. ${ }^{3}$ Cereal Health Research Center, Golestan University of Medical Sciences. ${ }^{4}$ Deputy of Research, Golestan University of Medical Sciences. ${ }^{5}$ Envrionmental Health Research Center, Golestan University of Medical Sciences, Gorgan, Islamic Republic of Iran.

Received: 19/11/16; accepted: 15/06/17 


\section{Introduction}

Obesity is now a global problem and the World Health Organization (WHO) has reported that $\sim 300$ million people worldwide are affected (1). Overweight and obesity have increased the risk of cardiovascular disease, dyslipidaemia, hypertension and type 2 diabetes mellitus (2). Women might be at greater risk of overweight and obesity than men are (3). Even developing countries such as the Islamic Republic of Iran are affected by the pandemic (4). It has been shown that $34 \%$ of Iranian women have body mass index $(\mathrm{BMI})>25 \mathrm{~kg} / \mathrm{m}^{2}$ (5). Cardiovascular disease is the most important cause of mortality among women (5). Iranian women are 3-4 times more likely to suffer from cardiovascular disease compared to women in other areas of the world (6).

Lack of physical activity (PA) is one of the leading causes of obesity. An $80 \%$ decrease in modifiable risk factors including unhealthy diet and lack of PA could reduce the risk of premature heart disease (7). WHO estimates that $31 \%$ of adults aged $>15$ years are sedentary ( 8 ) and $\sim 60 \%$ of people worldwide do not meet the recommended daily minimum level of PA (9). Sedentary lifestyle is recognized as a serious challenge in the Islamic Republic of Iran (10). Regular PA is an effective method for prevention of obesity and associated disease (11), and also its wider benefits have been acknowledged (12).

Counselling or education can improve physical activity status (13). Health promotion attempts to modify health-promoting and unhealthy behaviour. Therefore, health promotion research has been designed and implemented to follow or modify healthy behaviour. The Health Belief Model has been used for the study of health promotion behaviour and then revised as the Protection Motivation Theory (PMT) $(14,15)$. The PMT applies an individual's perception of fear in response to health threats. Fear means motivating or persuading persons to either engage in or adopt behaviour that is determined by the person's belief in the ability of that behaviour to reduce the fear caused by the health threat (16). The aforementioned cognitive process justifies the rationale for the selection of the PMT in the current survey. We also assumed that because PMT is a good predictor of dietary (17) and physical (16) activity, then it would also be a good predictor of overweight and obesity.

Motivational interviewing is a client-oriented and directive method to resolve the individual's ambivalence and increase intrinsic motivation (18). Motivational interviewing has frequently been used in the health area, with beneficial outcomes (18). The number of scientific articles published in this field in the past 3 years has doubled (19). Thus, we sought to investigate the effect of motivational interviewing on attitude and intention toward regular PA based on PMT among women with overweight and obesity who attended urban health centres.

\section{Methods}

\section{Study design}

We carried out a single-blind, randomized control trial between December 2013 and February 2015 in Gorgan City, Islamic Republic of Iran (Iranian Registry of Clinical Trials code IRCT2015061517736N5). All participants were selected using convenience sampling. All 6 health centres in Gorgan City were considered and 2 were selected (Centres 1 and 6) using a simple random sampling technique. Women are the major users of health centres in the Islamic Republic of Iran because of the type of services provided, such as childhood vaccination and child care.

\section{Participants}

Inclusion criteria were as follows: (1) BMI $25-29.9 \mathrm{~kg} / \mathrm{m}^{2}$ (overweight) or $30-35 \mathrm{~kg} / \mathrm{m}^{2}$ (obese); (2) being literate and (3) ability to exercise. Exclusion criteria were: (1) pregnancy and (2) absence from $>1$ session (standard and motivational interviewing). There were 30 participants in the control group and 30 in the motivational interviewing group. At 2 months follow-up, 2 women were excluded from the control group due to absence from $>1$ session. In the motivational interviewing group, 1 woman was excluded due to migration to another city. No women were lost at 6 months follow-up.

\section{Sample size}

According to Navidian et al. (20) and the estimation of mean self-efficacy of 57.9 (standard deviation, 34.9) in the intervention group and 44.06 (8.68) in the control group, $95 \%$ confidence interval, $95 \%$ test power, 30 women in each group and 60 participants in total were considered necessary.

$$
n=\frac{\left(s_{1}^{2}+s_{2}^{2}\right)\left(z_{1-\frac{\alpha}{2}}+z_{1-\beta}\right)^{2}}{\left(\bar{x}_{1}-\bar{x}_{2}\right)^{2}}
$$

Where $s_{1}$ and $s_{2}$ are the variances of the two groups, $Z_{1-\frac{a}{2}}$ is the confidence level, is the test $Z_{1-\beta}^{2}$ power, and $x_{1}$ and $x_{2}$ are the means of the two groups.

\section{Interventions}

The control group received a standard weight-control programme regarding exercise and its beneficial effects on obesity, comprising 2 1-hour sessions per week for 2 weeks. Each session was delivered by a health education specialist. At the end of the sessions, the participants had access to the researchers for asking questions. Motivational interviewing consisted of 5 sessions of 45-60 minutes executed by a psychologist for 7-10 of women for each session held during 2 weeks. A pamphlet designed based on PMT constructs was distributed to all participants. Its 
content described the effect of PA in controlling and preventing overweight and obesity. The motivational interviewing group also received the same standard weight-control programme as the control group (4 sessions).

\section{Variables definition}

Educational status of participants was classified into 4 levels: elementary school, middle school, high school and university. Current occupation was categorized as housewife, employed, unemployed, retired or others (such as nongovernmental organization). Marital status was classified as single or married. Definitions of overweight and obesity were based on the WHO criteria of $25 \leq \mathrm{BMI}<30 \mathrm{~kg} / \mathrm{m}^{2}$ for overweight and $\mathrm{BMI} \geq 30 \mathrm{~kg} / \mathrm{m}^{2}$ for obesity (21). Intention toward regular PA was defined as intention to do at least 30 minutes of moderate exercise at least once a week, 3-5 times a week (16).

\section{Anthropometric measurements}

Anthropometric measurements were made by an appropriately trained person. Weight was measured to the nearest $0.1 \mathrm{~kg}$ using a digital scale, with the women dressed in lightweight clothing. Height was calculated without shoes to the nearest millimetre using a height rod. Waist circumference was measured at the midpoint between the lower costal margin and the top of the iliac crest in a standing position. BMI was the ratio of weight $(\mathrm{kg})$ to square of height (m). Waist girth was measured at the minimum circumference between the iliac crest and the rib cage, and hip girth at the maximum width over the greater trochanters. Waist to hip ratio was then calculated.

\section{Questionnaire}

The questionnaire was designed and developed using 7 constructs of PMT theory: (1) sociodemographic characteristics; (2) perceived susceptibility
(28 questions; range 28-140); (3) perceived severity (29 questions; range 29-145); (4) self-efficacy (10 questions; range 10-50); (5) perceived response efficacy ( 8 questions; range $8-40)$; (6) intention (2 questions; range 2-10); and (7) attitude toward PA (10 questions; range 10-50). All parts of the questionnaire were scored $1-5$ based on a 5-point Likert scale comprising: completely agree, agree, no comment, disagree and completely disagree. Two main variables of the present survey comprising intention and attitude toward regular PA were measured by questions such as: "I intend to increase PA in the 2 future months" for intention, and "PA is an effective way to decrease the risk of obesity" for attitude.

Face validity ( 5 specialists commented) and content validity (10 specialists commented) were tested, and content validity rate and content validity index were calculated. Reliability of the questionnaire was studied using internal homogeneity and Cronbach's $\alpha$ and the values of these coefficients were also calculated for all structures. Cronbach's $\alpha$ was $0.83,0.89,0.78$ and 0.88 for perceived susceptibility, perceived severity, perceived response efficacy and intention, respectively. The highest a was for perceived self-efficacy (0.94) and the lowest was for attitude toward PA (0.73).

\section{Ethical approval}

The study protocol was approved by the Ethical Committee of the Golestan University of Medical Science (no 930417063). Written informed consent was obtained from all women before participation in the study.

\section{Data analysis}

Sociodemographic characteristics and anthropometric data were descriptively reported as mean, standard deviation and percentage. The KolmogorovSmirnov test was used to test the normal distribution of the data such as age, BMI, weight, waist circumference and waist-to-hip ratio, and the constructs of the theory. One-way analysis of variance (ANOVA) was also used to explore the normality of the data (constructs and anthropometric characteristics) at baseline. Repeated measures ANOVA was used to compare anthropometrics characteristics and PMT constructs at 3 times during the survey. Bonferroni test was carried out to assess the changes in constructs at 3 times during the study (comparing pre-intervention with 2and 6-months follow-up, and 2-months follow-up with 6-months follow-up). A logistic regression model was used to test the relative importance of the theory constructs that predicted the women's intention toward regular PA. A P value $\leq 0.05$ was defined as significant.

\section{Results}

\section{Baseline characteristics}

Baseline characteristics of the control and motivational interviewing groups are shown in Table 1. The mean age of the women was 37.95 (8.78) years (range 21-54) and mean BMI was $28.54(2.06) \mathrm{kg} / \mathrm{m}^{2}$ (range 26-33). Most women in the 2 groups had an academic education, were employed and were married.

\section{Change in PMT constructs using repeated measures ANOVA}

Repeated measures ANOVA revealed that all PMT constructs comprising perceived susceptibility, perceived severity, self-efficacy, perceived response efficacy, intention and attitude were significantly different in the 2 groups before intervention and at 2 - and 6-months follow-up (Table 2). Bonferroni findings revealed that there were significant associations between the 3 times for severity and susceptibility constructs (between pre-intervention and 2-and 6-months follow-ups as well as between 2-and 6-monthd followup) $(P=0.001)$. For the constructs of 


\begin{tabular}{|c|c|c|c|}
\hline Variables & $\begin{array}{c}\text { Motivational interviewing group } \\
(n=30) \\
\text { Mean (SD) }\end{array}$ & $\begin{array}{c}\text { Control group }(n=30) \\
\text { Mean }(\text { SD) }\end{array}$ & $P$ \\
\hline Age, yr & $37.20(8.08)$ & $39.03(9.25)$ & $0.425^{* *}$ \\
\hline Body mass index, $\mathrm{kg} / \mathrm{m}^{2}$ & $28.59(1.81)$ & $28.50(2.32)$ & $0.873^{* *}$ \\
\hline Weight, kg & 76.05 (6.99) & $74.93(7.16)$ & $0.543^{* *}$ \\
\hline Waist circumference, $\mathrm{cm}$ & $84.47(9.24)$ & $79.97(7.01)$ & $0.038^{* *}$ \\
\hline Waist-to-hip ratio & $0.79(0.04)$ & $0.82(0.04)$ & $0.045^{* *}$ \\
\hline Education & n (\%) & $\mathrm{n}(\%)$ & \multirow{4}{*}{$0.706^{*}$} \\
\hline Elementary and middle school & $4(13.3)$ & $7(23.3)$ & \\
\hline High school & $10(33.4)$ & $8(26.7)$ & \\
\hline Academic & $16(53.3)$ & $15(50)$ & \\
\hline Job & n (\%) & $\mathrm{n}(\%)$ & \multirow{5}{*}{$0.783^{*}$} \\
\hline Housewife & - & - & \\
\hline Employed & $20(66.7)$ & $17(56.7)$ & \\
\hline Unemployed & $6(20)$ & $6(20)$ & \\
\hline Other & $4(13.3)$ & $7(23.3)$ & \\
\hline Marital status & $\mathrm{n}(\%)$ & $\mathrm{n}(\%)$ & \multirow{3}{*}{$0.739 *$} \\
\hline Single & $5(16.7)$ & $6(20)$ & \\
\hline Married & $25(83.3)$ & $24(80)$ & \\
\hline
\end{tabular}

* $\chi^{2}$ test.

**Independent t test.

\begin{tabular}{|c|c|c|c|c|c|c|c|c|}
\hline \multirow[t]{2}{*}{ Constructs } & \multirow[t]{2}{*}{ Group } & \multicolumn{2}{|c|}{ Pre-intervention } & \multicolumn{2}{|c|}{ 2-mo follow-up } & \multicolumn{2}{|c|}{ 6-mo follow-up } & \multirow[t]{2}{*}{$P$} \\
\hline & & Mean & SD & Mean & SD & Mean & SD & \\
\hline \multirow[t]{3}{*}{ Perceived susceptibility } & Control & $92.43^{*}$ & 11.95 & 90.28 & 11.77 & $81.96^{* *}$ & 9.90 & \multirow[t]{3}{*}{$0.001 \mathrm{a}$} \\
\hline & MI & 90.76 & 14.47 & 108.8 & 11.04 & 108.3 & 10.72 & \\
\hline & Total & 91.60 & 13.1 & 99.86 & 14.65 & 95.40 & 16.80 & \\
\hline \multirow[t]{3}{*}{ Perceived severity } & Control & $94.20^{*}$ & 12.59 & $93.71^{* *}$ & 12.22 & $85.35^{* * *}$ & 11.94 & \multirow[t]{3}{*}{0.001} \\
\hline & MI & 93.43 & 14.83 & 114.5 & 10.38 & 112.4 & 12.44 & \\
\hline & Total & 93.81 & 13.65 & 104.4 & 15.35 & 99.12 & 18.23 & \\
\hline \multirow[t]{3}{*}{ Perceived self-efficacy } & Control & $20.96^{*}$ & 7.00 & $29.21^{* *}$ & 8.17 & 27.89 & 7.42 & \multirow[t]{3}{*}{$0.001 \mathrm{a}$} \\
\hline & MI & 22.26 & 7.35 & 37.40 & 7.33 & 39.27 & 6.11 & \\
\hline & Total & 21.61 & 7.15 & 33.44 & 8.72 & 33.68 & 8.84 & \\
\hline \multirow{3}{*}{$\begin{array}{l}\text { Perceived response } \\
\text { efficacy }\end{array}$} & Control & $17.13^{*}$ & 4.98 & $23.57^{* *}$ & 6.11 & 23.00 & 3.35 & \multirow[t]{3}{*}{0.001} \\
\hline & MI & 17.06 & 4.77 & 30.63 & 5.31 & 30.48 & 3.51 & \\
\hline & Total & 17.10 & 4.83 & 27.22 & 6.69 & 26.80 & 5.08 & \\
\hline \multirow[t]{3}{*}{ Intention } & Control & $4.00^{*}$ & 1.43 & $6.17^{* *}$ & 1.80 & 5.87 & 1.50 & \multirow[t]{3}{*}{$0.001 \mathrm{a}$} \\
\hline & MI & 4.46 & 1.69 & 8.40 & 1.13 & 8.75 & 0.98 & \\
\hline & Total & 4.23 & 1.57 & 7.32 & 1.85 & 7.33 & 1.93 & \\
\hline \multirow[t]{3}{*}{ Attitude } & Control & 20.73 & 4.10 & $20.73^{* *}$ & 4.10 & $26.96^{* * *}$ & 6.45 & \multirow[t]{3}{*}{$0.001 a$} \\
\hline & MI & 21.23 & 5.23 & 21.23 & 5.23 & 39.75 & 5.79 & \\
\hline & Total & 20.98 & 4.67 & 20.98 & 4.67 & 33.47 & 1.17 & \\
\hline
\end{tabular}

${ }^{a}$ Repeated measures analysis of variance.

* Bonferroni test (pre-intervention and 2-months follow-up) $(P \leq 0.001)$.

${ }^{* *}$ Bonferroni test (pre-intervention and 6-months follow-up) $(P \leq 0.001)$.

${ }^{* * * B}$ Bonferroni test (2- and 6-months follow-up) $(P \leq 0.001)$.

MI = motivational interviewing 
perceived self-efficacy, perceived susceptibility, response efficacy, attitude and intention toward regular $\mathrm{PA}$, there were significant relationships between pre-intervention and 2- and 6-months follow-up $(P<0.001)$, but not between 2 - and 6-months follow-up.

\section{Changes in anthropometric characteristics}

Weight, waist circumference and waist-to-hip ratio differed significantly between the 2 study groups such that they were decreased more in the motivational interviewing group compared to the control group, whereas BMI did not differ significantly(Table 3 ).

\section{Predicting regular PA intention based on the PMT constructs using linear regression models}

We entered all PMT constructs into the linear regression model using the forward method (Table 4). Perceived response efficacy $(P<0.001)$, perceived severity $(P=0.014)$ and perceived selfefficacy $(P=0.043)$ predicted the women's intention to participate in regular PA at 2-months follow-up. At 6-months follow-up, attitude $(P<0.001)$ and perceived severity $(P=0.020)$ were the only predictors of $\mathrm{PA}$. The strongest predictors of women's intention to do regular PA were perceived response efficacy $(\beta=1.398)$ and attitude $(\beta=$ $0.729)$ at 2 - and 6-months follow-up.

\section{Predicting attitude toward regular PA based on the PMT constructs using linear regression models}

We entered all PMT constructs into the linear regression model using the forward method (Table 5). Perceived self-efficacy $(P=0.009)$ was the only predictor of attitude toward regular PA at 2-months follow-up. Perceived self-efficacy $(P<0.001)$ and perceived susceptibility $(P=0.042)$ were predictors of PA at 6-months follow-up. Perceived self-efficacy $(\beta=0.807)$ was the stronger of the 2 predictors.

\section{Discussion}

We utilized the PMT to find factors that determined the intention of women attending urban health centres in Gorgan to do regular PA. To the best of our knowledge, the current investigation is the first survey using PMT in the Islamic Republic of Iran focusing on regular PA by women.
In our study, at 2-months followup, perceived response efficacy, selfefficacy and severity were predictors of intention to do PA. This agrees with a meta-analysis of 65 related studies representing $>20$ health issues (22). Increases in constructs such as perceived severity, perceived susceptibility, response efficacy, and self-efficacy simplified adaptive intentions or behaviours (23). In a study conducted by Yan et al. (22) in China, smoking intention was predicted by PMT constructs (severity, susceptibility, intrinsic rewards, extrinsic rewards, self-efficacy, response efficacy, and response cost), which is similar to our findings. In a review carried out by Cox et al. (24), PMT predictors of intention to consume functional foods explained 59-63\% of the variance, and self-efficacy was the strongest predictor. Attitude was the strongest predictor of intention in our survey after 6-months follow-up, which might be explained by the fact that attitude change requires a long time compared to other constructs. Mirkarimi et al. (19) and Park et al. (25) reported that perceived selfefficacy and response efficacy were the strongest predictors of women's intention to follow weight-loss programmes and intention toward functional food

\begin{tabular}{|c|c|c|c|c|c|c|c|c|}
\hline \multirow[t]{2}{*}{ Constructs } & \multirow[t]{2}{*}{ Group } & \multicolumn{2}{|c|}{ Pre-intervention } & \multicolumn{2}{|c|}{ 2-mo follow-up } & \multicolumn{2}{|c|}{ 6-mo follow-up } & \multirow[t]{2}{*}{$P$} \\
\hline & & Mean & SD & Mean & SD & Mean & SD & \\
\hline \multirow[t]{3}{*}{ BMI } & Control & 28.39 & 2.35 & 27.74 & 2.21 & 27.60 & 2.11 & $0.938 *$ \\
\hline & MI & 28.58 & 1.84 & 27.75 & 1.72 & 27.52 & 1.71 & \\
\hline & Total & 28.49 & 2.09 & 27.75 & 1.96 & 27.56 & 1.90 & \\
\hline \multirow[t]{3}{*}{ Weight } & Control & 74.70 & 7.35 & 72.98 & 6.58 & 72.75 & 6.53 & $0.001^{*}$ \\
\hline & MI & 76.22 & 7.06 & 73.89 & 6.54 & 72.96 & 5.92 & \\
\hline & Total & 75.47 & 7.18 & 73.44 & 6.51 & 72.86 & 6.17 & \\
\hline \multirow[t]{3}{*}{ Waist circumference } & Control & 79.79 & 7.21 & 77.82 & 6.35 & 77.39 & 6.36 & $0.001^{*}$ \\
\hline & MI & 84.24 & 9.32 & 82.00 & 8.78 & 77.96 & 17.10 & \\
\hline & Total & 82.05 & 8.58 & 79.95 & 7.90 & 77.68 & 12.88 & \\
\hline \multirow[t]{3}{*}{ WHR } & Control & 0.823 & 0.046 & 0.812 & 0.042 & 0.809 & 0.042 & $0.001^{*}$ \\
\hline & MI & 0.800 & 0.045 & 0.781 & 0.045 & 0.774 & 0.047 & \\
\hline & Total & 0.811 & 0.046 & 0.796 & 0.046 & 0.791 & 0.047 & \\
\hline
\end{tabular}

*Repeated measures analysis of variance.

$B M I=$ body mass index $; M I=$ motivational interviewing; $W H R=$ waist-to-hip ratio . 


\begin{tabular}{|c|c|c|c|}
\hline \multirow[t]{2}{*}{ Constructs of the PMT } & \multirow{2}{*}{$\begin{array}{c}\text { Unstandardized } \\
\text { coefficients } \\
\beta\end{array}$} & \multicolumn{2}{|c|}{ Standardized coefficients } \\
\hline & & $\beta$ & $\boldsymbol{P}$ \\
\hline \multicolumn{4}{|l|}{ 2-mo follow-up } \\
\hline Constant & 0.760 & & 0.480 \\
\hline Perceived response efficacy & 0.388 & 1.398 & 0.001 \\
\hline Perceived severity & 0.027 & 0.220 & 0.014 \\
\hline Perceived self-efficacy & 0.157 & 0.738 & 0.043 \\
\hline \multicolumn{4}{|l|}{ 6-mo follow-up } \\
\hline Constant & 0.106 & & \\
\hline Attitude & 0.159 & 0.729 & 0.001 \\
\hline Perceived severity & 0.021 & 0.203 & 0.020 \\
\hline
\end{tabular}

$P A=$ physical activity $; P M T=$ protection motivation theory.

consumption, which is similar to our present findings.

In the current study, all constructs of the PMT were significantly different between the 2 study groups. This agrees with the survey of Milne et al. (26) that combined motivational and volitional interventions to promote exercise participation. That study presented remarkable differences between the control, motivational interviewing and volitional intervention groups for all the PMT variables about intention and behaviour. Gaston et al. (27) confirmed the beneficial effect of motivational intervention based on the PMT with volitional intervention to promote exercise during pregnancy. They reported that a PMT-centred intervention was not sufficient to bring about behaviour modification and it must be accompanied by action and coping planning. This might have been caused by 2 different samples in our study (obese and overweight women) and in theirs (pregnant women). Mirkarimi et al. (19) also revealed that all constructs of the PMT were changed significantly after intervention in the motivational interviewing and motivation-intention groups compared to the control group. A meta-analysis of weight-loss interventions exploring diet only with diet and PA reported medium changes of 1.64 $\mathrm{kg}$ or $1.24 \mathrm{~kg} / \mathrm{m}^{2}$ after a combination of dietary and augmented PA (28).

We found that all anthropometric characteristics (except for BMI) were significantly different after intervention between the 2 groups, such that women in the motivational interviewing group lost more weight and also showed improved indices such as waist circumference and waist-to-hip ratio at 2- and 6-months follow-up. Also, Bonferroni test revealed significant differences at the 3 times of the survey. Moreover, the decrease in BMI or weight loss was greater in the motivational interviewing than the control group. Carels et al. (29) explained that motivational interviewing was effective for people who failed to achieve weight loss through standard programmes, and that they participated in the PA programme, which is in line with our results. Di Marco et al. (30) presented a medium effect of motivational interviewing on BMI, and concluded that it had greater efficacy than traditional treatments.

\begin{tabular}{|c|c|c|c|}
\hline \multirow[t]{2}{*}{ Constructs of the PMT } & \multirow{2}{*}{$\begin{array}{c}\text { Unstandardized } \\
\text { coefficients } \\
\beta\end{array}$} & \multicolumn{2}{|c|}{ Standardized coefficients } \\
\hline & & $\beta$ & $\boldsymbol{P}$ \\
\hline \multicolumn{4}{|l|}{ 2-mo follow-up } \\
\hline Constant & 14.819 & & 0.001 \\
\hline Perceived self-efficacy & 0.185 & 0.340 & 0.009 \\
\hline \multicolumn{4}{|l|}{ 6-mo follow-up } \\
\hline Constant & 1.293 & & 0.676 \\
\hline Perceived self-efficacy & 0.808 & 0.807 & 0.001 \\
\hline Perceived susceptibility & 0.079 & 0.150 & 0.042 \\
\hline
\end{tabular}


We showed that anthropometric changes in the motivational interviewing group were more stable than those in the control group, which has also been shown in other studies $(20,31)$.

Our study had some limitations. First, this survey relied upon a self-administered questionnaire (albeit valid) and objective methods might have been preferable. Second, we only included women, which may limit the generalization of the results beyond this survey. It is better to conduct long-term follow-up of PA after implementing motivational interviewing. Despite these limitations, the study protocol was approved by the Iranian Registry of Clinical Trials. A benefit of this survey was that it was the first to utilize PMT as a theoretical framework to study PA in the Islamic Republic of Iran and may be used as a basis to explore other populations such as teenagers or adults that might be more at risk.

In conclusion, our findings suggest that PMT constructs could be effective in predicting intention to undertake regular PA among women with overweight and obesity. However, further studies should be implemented with the other populations mentioned above to confirm the application of the PMT.
Factors influencing the intention to undertake regular PA should continue to be investigated until age- and gendertailored strategies can be developed to improve PA in more populations.

\section{Acknowledgements}

We gratefully acknowledge the assistance of the participants and experts in identifying obese and overweight women who were eligible for the study.

\section{Funding: None.}

Competing interests: None declared.

\section{References}

1. Lippa NC, Sanderson SC. Impact of information about obesity genomics on the stigmatization of overweight individuals: an experimental study. Obesity (Silver Spring). 2012 Dec;20(12):2367-76. PMID:22673191

2. Sotoudeh G, Khosravi S, Khajehnasiri F, Khalkhali HR. High prevalence of overweight and obesity in women of Islamshahr, Iran. Asia Pac J Clin Nutr. 2005;14(2):169-72. PMID:15927935

3. Wolongevicz DM, Zhu L, Pencina MJ, Kimokoti RW, Newby PK, D'Agostino RB, et al. Diet quality and obesity in women: the Framingham Nutrition Studies. Br J Nutr. 2010 Apr;103(8):12239. PMID:19930766

4. Mollaei E, Hosseini SA, Roohi Gh. The relationship between body mass index (BMI) and co-morbidities of obesity in residents of Gorgan. J Jahrom Univ. Med Sci. 2010;8(11):2733 (http://jmj.jums.ac.ir/browse.php?a_id=733\&sid=1\&slc_ lang=en).

5. Ferdosian S, Kimiagar SM. Contributing factors to BMI decrease in women undergoing weight loss program. J Kerman Univ Med Sci.2011;18(1):63-72 (http://www.kmusjournal.ir/ english/abstract.asp?articleID=3655).

6. Khodaveisi M, Yaghobi A, Borzou R. Prevalence of cardiovascular risk factors among Hamedeni adolescents. J School Public Health Inst Public Health Res.2011;8(4):31-9 (http://sjsph. tums.ac.ir/browse.php?a_id=67\&sid=1\&slc_lang=en).

7. Daniali SS, Azadbakht L, Mostafavi DF. The relationship between body image, self-efficacy and physical activity in female employees of Isfahan University of Medical Sciences and University of Isfahan, Iran. Health System Res. 2012;8(6):991-1001 (http://en.journals.sid.ir/ViewPaper.aspx?ID=348281).

8. Bastos JP, Araújo CLP, Hallal PC. Prevalence of insufficient physical activity and associated factors in Brazilian adolescents. J Phys Act Health. 2008 Nov;5(6):777-94. PMID:19164815

9. Dąbrowska-Galas M, Plinta R, Dąbrowska J, SkrzypulecPlinta V. Physical activity in students of the Medical University of Silesia in Poland. Phys Ther. 2013 Mar;93(3):384-92. PMID:23086407

10. Momenan AA, Delshad M, Mirmiran P, Ghanbarian A, Azizi F. Leisure time physical activity and its determinants among adults in Tehran: Tehran Lipid and Glucose Study. Int J Prev Med. 2011Oct;2(4):243-51. PMID:22174964
11. Allender S, Rayner M. The burden of overweight and obesityrelated ill health in the UK. Obes Rev. 2007 Sep;8(5):467-73. PMID:17716304

12. Koeneman MA, Verheijden MW, Chinapaw MJ, HopmanRock M. Determinants of physical activity and exercise in healthy older adults: a systematic review. Int J Behav Nutr Phys Act. 2011 Dec28;8(1):142. PMID:22204444

13. Weinstock RS, Brooks G, Palmas W, Morin PC, Teresi JA, Eimicke JP, et al. Lessened decline in physical activity and impairment of older adults with diabetes with telemedicine and pedometer use: results from the IDEATel study. Age Ageing. 2010;0:1-7. PMID:21081539

14. Rogers RW. A protection motivation theory of fear appeals and attitude change. J Psychol. 1975Sep;91(1):93-114. PMID:28136248

15. Maddux JE, Rogers RW. Protection motivation and self-efficacy: a revised theory of fear appeals and attitude change. J Exp Soc Psychol. 1983;19(5):469-79 (http://www.sciencedirect. com/science/article/pii/0022103183900239).

16. Redd BR. Using the protection motivation theory to examine the effects of obesity fear arousal on the physical activity of young adult female college students [thesis]. Detroit: Wayne State University; 2012.

17. Yoon E. Food defense management plan implementation intention: an application of protection motivation theory [thesis]. Seoul: Kyonggi University; 2007.

18. Martins RK, McNeil DW. Review of motivational interviewing in promoting health behaviors. Clin Psychol Rev. 2009 Jun;29(4):283-93. PMID:19328605

19. Mirkarimi K, Mostafavi F, Eshghinia S, Vakili MA, OzouniDavaji RB, Aryaie M. Effect of motivational interviewing on a weight loss program based on the protection motivation theory. Iran Red Crescent Med J. 2015 Jun 23;17(6):e23492. PMID:26380106

20. Navidian A, Abedi M, Baghban I, Fatehizadeh M, Poursharifi $\mathrm{H}$, Dehkordi $M$. Effects of motivational interviewing on weight loss of individuals suffering. Iran J Nutr Sci Food Technol.2010;5(2):45-52 (https://nsft.sbmu.ac.ir/browse.php?a $\mathrm{id}=325 \&$ slc_lang=en $\&$ sid $=1 \&$ printcase $=1 \& \mathrm{hbnr}=1 \& \mathrm{hmb}=1) \quad($ in Persian). 
21. Lee SA, Wen W, Xu WH, Zheng W, Li H, Yang G, et al. Prevalence of obesity and correlations with lifestyle and dietary factors in Chinese men. Obesity (Silver Spring). 2008 Jun;16(6):1440-7. PMID:18356829

22. Yan Y, Jacques-Tiura AJ, Chen X, Xie N, Chen J, Yang N, et al. Application of the protection motivation theory in predicting cigarette smoking among adolescents in China. Addict Behav. 2014 Jan;39(1):181-8. PMID:24157424

23. Floyd DL, Prentice-Dunn S, Rogers RW. A meta-analysis of research on protection motivation theory. J Appl Soc Psychol. 2000;30(2):407-29 (http://onlinelibrary.wiley.com/ doi/10.1111/j.1559-1816.2000.tb02323.x/abstract).

24. Cox DN, Koster A, Russell CG. Predicting intentions to consume functional foods and supplements to offset memory loss using an adaptation of protection motivation theory. Appetite. 2004 Aug;43(1):55-64. PMID:15262018

25. Park O-H, Hoover L, Dodd T, Huffman L, Feng D. The use of the modified protection motivation theory to explore adult consumers' functional foods consumption behavior. In: 16th Graduate Students Research Conference, Houston, TX, 6-8 Jan, 2011 (http://scholarworks.umass.edu/cgi/viewcontent. cgi article $=1234 \&$ context $=$ gradconf_hospitality, accessed 27 Jun 2017).
26. Milne S, Orbell S, Sheeran P. Combining motivational and volitional interventions to promote exercise participation: protection motivation theory and implementation intentions. Br J Health Psychol. 2002 May; 7(Pt 2):163-84. PMID:14596707

27. Gaston A, Prapavessis H. Using a combined protection motivation theory and health action process approach intervention to promote exercise during pregnancy. J Behav Med. 2014 Apr;37(2):173-84. PMID:23180287

28. Norris SL, Zhang X, Avenell A, Gregg E, Schmid CH, Lau J. Long-term non-pharmacological weight loss interventions for adults with prediabetes. Cochrane Database Syst Rev. 20050418;2(2):CD005270. PMID:15846748

29. Carels RA, Darby L, Cacciapaglia HM, Konrad K, Coit C, Harper $\mathrm{J}$, et al. Using motivational interviewing as a supplement to obesity treatment: a stepped-care approach. Health Psychol. 2007 May;26(3):369-74. PMID:17500624

30. DiMarco ID, Klein DA, Clark VL, Wilson GT. The use of motivational interviewing techniques to enhance the efficacy of guided self-help behavioral weight loss treatment. Eat Behav. 2009 Apr;10(2):134-6. PMID:19447358

31. West DS, DiLillo V, Bursac Z, Gore SA, Greene PG. Motivational interviewing improves weight loss in women with type 2 diabetes. Diabetes Care. 2007May;30(5):1081-7. PMID:17337504 